\title{
Study of association of physical activity with indicators of body composition and metabolic syndrome in subjects with sedentary job profile
}

\author{
Mukesh Kumar ${ }^{1, *}$, Jeewandeep Kaur ${ }^{2}$, Rakesh kumar ${ }^{3}$ \\ ${ }^{1}$ Professor, ${ }^{2}$ Assistant Professor, ${ }^{3}$ Demonstrator, Dept. of Physiology, BPS, Govt. Medical College(W), Sonepat, \\ Haryana, India
}

*Corresponding Author:

Email: mkumar5031@ rediffmail.com

\begin{abstract}
Objective: The benefits of physical activity and physical fitness on the health of general population are provided with evidence.

We investigated association of leisure time physical activity with indicators of body composition and metabolic syndrome among less active, moderately active and active groups.

Design: Analysis of cross sectional self reported physical activity index and measured indicators of body composition and metabolic syndrome.

Subjects: A total of 100 male subjects, aged 25-50 years, who were part of a randomly selected sample and who agreed to participate in the study.

Measurements: Self reported measure of physical activity index, weight $(\mathrm{Kg})$, height (meter), pulse (manually), blood pressure (mercury sphygmomanometer), various biochemical parameters (i.e. serum triglycerides, and fasting plasma glucose) is measured in all the subjects.

Results: High levels of leisure time physical activity were positively associated with the likelihood of being in the normal body mass index and lower $\%$ body fat. When physical activity score was correlated with the component of metabolic syndrome, we observed that there was significantly negative correlation between physical activity score and Systolic and Diastolic blood pressure, serum triglycerides, fasting blood glucose.

Conclusion: This study shows association between body fat, body mass index and leisure time physical activity. Low physical activity is associated with increased risk of developing metabolic syndrome. These findings will have important public health implications for the development and targeting of weight gain prevention strategies and life style modification may be beneficial in avoiding the risk of metabolic syndrome and its consequences.
\end{abstract}

Keywords: Body composition, Metabolic syndrome, Physical activity.

Received: 23 $^{\text {rd }}$ October, 2017

\section{Introduction}

The factors associated with the risk of developing metabolic syndrome are overweight, altered lipid profile, high blood pressure and increase in blood glucose levels. All these factors are also leads to increase risk of cardiovascular diseases and type 2 Diabetes mellitus. ${ }^{1,2}$

Though various factors such as sedentary life style, genetic, unhealthy food are responsible for the condition of metabolic syndrome but the underlying patho-physiologic mechanism of syndrome is not clear. ${ }^{3,4}$

Sedentary life style is a major risk factor for various diseases 18. Due to development of modern electronic equipments and computers, the physical activity at work is reduced. Sedentary life style leads to overweight and obesity, which is a major risk factor for metabolic syndrome. ${ }^{5,6}$

Prevalence of metabolic syndrome in some regions of India ranges from 23.2 to $41.1 \%$ which is high and is particularly rising due to adoption of modernized life style.

The benefits of physical activity and physical fitness on health of general population are provided with evidence. ${ }^{7}$ The office workers in medical college are exposed to sedentary life style and wrong eating habits. Few studies are available about the incidence of metabolic syndrome in these employees.

This study was planned to see, if there is any correlation between physical activity and various risk factors of metabolic syndrome.

The purpose of the study was to see the effect of levels of physical activity on various components of metabolic syndrome.

\section{Materials and Methods}

This study was a cross sectional, comparative study. A synopsis of the study protocol was submitted to Institutional Ethical Committee and approval was obtained. One hundred male subjects in the age group 25-50 
years are selected randomly from the campus of BPS GMC for women Khanpur kalan sonepat. Before inclusion in the present study participants were excluded if they have any debilitating disease, chronic illness, hypothyroidism, hyperthyroidism etc. All the subjects were informed in detail about the purpose and procedure of the study. A written and informed consent was taken from the subjects prior to enrolment in the study.

\section{Procedure}

After inclusion in the study various parameters such as weight $(\mathrm{Kg})$, height (meter), pulse (manually), blood pressure (mercury sphygmomanometer), various biochemical parameters (i.e. serum triglycerides, serum high density lipoprotein cholesterol and fasting plasma glucose) and physical activity index score (questionnaire based) is measured in all the subjects. The questionnaire allows the assessment of self reported leisure time physical activity. A score of $<14$ units indicate an insufficient level of activity, 14-23 indicates moderate activity, > 24 indicates sufficient activity. The subjects are categorize accordingly into three groups i.e. insufficiently active, moderately active and active group..$^{8-10}$

Table 1: Comparison of mean $( \pm$ S.D) values of various parameters among different groups

\begin{tabular}{|l|l|l|l|l|}
\hline \multicolumn{1}{|c|}{ Parameters } & $\begin{array}{c}\text { Insufficiently } \\
\text { active }\end{array}$ & $\begin{array}{c}\text { Moderately } \\
\text { active }\end{array}$ & \multicolumn{1}{|c|}{ Active } & p-value \\
\hline Age (years) & $30.12 \pm 2.90$ & $32.35 \pm 3.10$ & $31.33 \pm 4.0$ & $>.05$ \\
\hline BMI & $23.77 \pm 2.40$ & $22.90 \pm 2.37$ & $21.50 \pm .90$ & $<.001$ \\
\hline SBP (mmHg) & $128.40 \pm 7.60$ & $120.55 \pm 8.10$ & $112.80 \pm 8.10$ & $<.001$ \\
\hline DBP (mmHg) & $80.40 \pm 7.95$ & $76.60 \pm 6.90$ & $72.11 \pm 5.05$ & $<.001$ \\
\hline $\begin{array}{l}\text { Serum } \\
\begin{array}{l}\text { Triglycerides (mg / } \\
\text { dl) }\end{array}\end{array}$ & $150.58 \pm 21.90$ & $140.41 \pm 18.33$ & $130.88 \pm 14.90$ & $<.001$ \\
\hline $\begin{array}{l}\text { Fasting blood } \\
\text { glucose (mg / dl) }\end{array}$ & $99.50 \pm 5.50$ & $92.21 \pm 6.65$ & $86 \pm 7.80$ & $<.001$ \\
\hline
\end{tabular}

Table 2: Correlation between physical activity score and components of metabolic syndrome

\begin{tabular}{|l|c|c|}
\hline \multicolumn{1}{|c|}{ Variable } & Pearson's & P value \\
\hline BMI & -0.37 & $<0.001$ \\
\hline SBP & -0.43 & $<0.001$ \\
\hline DBP & -0.29 & $<0.001$ \\
\hline Serum Triglycerides & -.44 & $<0.001$ \\
\hline FBG & 0.40 & $<0.001$ \\
\hline
\end{tabular}

Graph 1: Bar Diagram showing comparison of mean values of systolic blood pressure

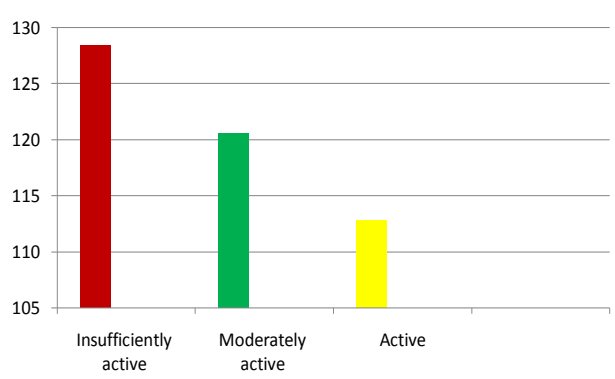

Graph 2: Bar Diagram showing comparison of mean values of BMI

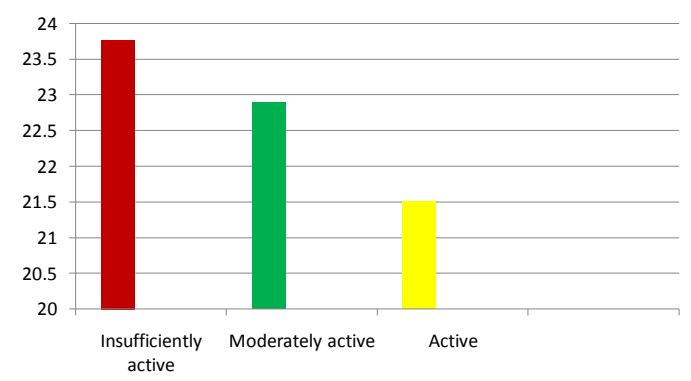


Graph 3: Bar Diagram showing mean values of Serum triglycerides

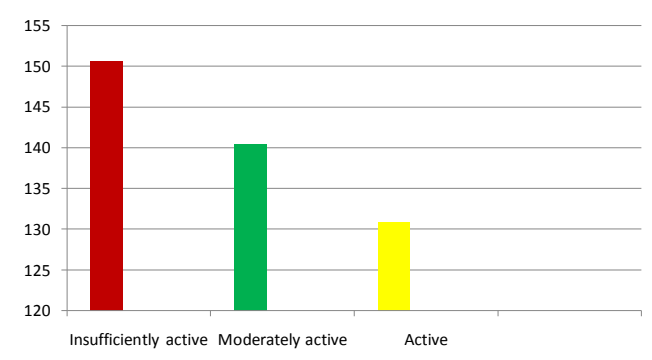

Graph 4: Bar diagram showing fasting blood glucose

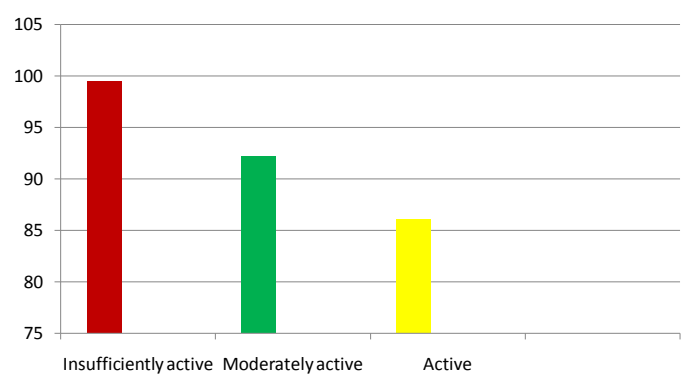

\section{Discussion}

The metabolic syndrome and its components are closely associated with low physical activity (PA) levels ${ }^{11}$ Because of increased automation and use of technology participation in physical activities has declined. Time spent at sedentary occupations has been increasing and may be expected to have a negative impact on total physical activity. ${ }^{12}$ Low levels of physical activity contribute to overweight and obesity and strong evidence exists to show that obesity is a major risk factor for metabolic syndrome ${ }^{13}$ Metabolic syndrome is predictive of progression to Type 2 Diabetes Mellitus (DM), Hypertension (HTN) and Coronary Artery Diseases (CAD). ${ }^{14}$

In the present study subjects were grouped according to their physical activity score using a standard questionnaire, the groups under study were insufficiently active, moderately active and active groups.

In our study the difference in mean values of age was statistically non-significant in subjects of the three groups whereas the difference in mean values of BMI was statistically highly significant among the three groups.

We found that mean value of systolic blood pressure and diastolic was significantly higher in insufficiently active group as compared to moderately active group and active group $(p<0.001)$. We also observed that moderately active group had statistically significant higher mean value of systolic blood pressure and statistically non significant higher values of Diastolic blood pressure as compared to active group $(\mathrm{p}<0.05)$.

The mean value of serum triglycerides and fasting plasma glucose was significantly higher in insufficiently active group as compared to moderately active group and active group $(p<0.001)$. Also, moderately active group when compared with active group have statistically non-significant higher values ( $\mathrm{p}>0.05)$.

Table 2 shows the correlation of physical activity score with components of metabolic syndrome. Correlation was done by taking physical activity score as independent variable and metabolic syndrome components as dependent variable. The result shows that there was statistically significant negative correlation between physical activity score and BMI $(\mathrm{r}=$ $0.37, \mathrm{p}<0.001)$, systolic blood pressure $(\mathrm{r}=0.43$, $\mathrm{p}<0.001)$, diastolic blood pressure $(\mathrm{r}=0.29$, $\mathrm{p}<0.001)$, serum triglyceride $(\mathrm{r}=0.44, \mathrm{p}<0.001)$, and fasting plasma glucose $(r=0.40, p<0.001)$.

To summarize, in the present study we observed that the mean values of components of metabolic syndrome (i.e. waist circumference, systolic blood pressure, diastolic blood pressure, serum triglycerides and fasting plasma glucose) were significantly higher in insufficiently active group as compared to moderately active and active group. When we compared moderately active group with active group we observed that mean values of waist circumference, diastolic blood pressure, serum triglycerides and fasting plasma glucose were higher in moderately active group as compared to active group but the difference was not statistically significant. However mean value of systolic blood pressure was significantly higher in moderately active group as compared to active group.

When physical activity score was correlated with the components of metabolic syndrome, we observed that there was statistically significant negative correlation between physical activity score and waist circumference, systolic blood pressure, diastolic blood pressure, serum triglyceride and fasting plasma glucose. When we studied correlation of physical activity score with body mass index, we found that physical activity score was significantly negatively correlated with body mass index. In our study, we also observed that body mass index was significantly positively correlated with waist circumference, systolic blood pressure, diastolic blood pressure, serum triglyceride and serum fasting plasma glucose. 
Mohan $\mathrm{V}$ et al also observed that subjects with light grade exercise had a significant higher fasting plasma glucose and body mass index as compared to those with heavy garde and moderate grade exercise. ${ }^{15}$

Cherell D et al in their study observed that mean triglyceride concentrations were lower in men and women with moderate and high levels of physical activity as compared to men and women with low levels of physical activity. ${ }^{16}$

\section{Conclusion}

To conclude, metabolic syndrome involves risk for development of cardiovascular diseases and type 2 diabetes mellitus. Low physical activity is associated with increased risk of developing metabolic syndrome. So regular physical activity and lifestyle modifications may be beneficial in avoiding the risk of metabolic syndrome.

\section{Limitations of the study}

Dietary habits and genetic factors which can also affect the results should have been considered. The significance of study can further be expanded considering these factors.

\section{References}

1. Alberti KG. Zimmet P, Shaw J. The metabolic syndrome-a new worldwide defimition. Lancet.2005;366:1059-62

2. Harmonizing metabolic syndrome. A Joint Interim Statement of the International Diabetes Federation Task Force o Epidemiology and Prevention; National Heart, Lung, and Blood Institute; American Heart Association; World Heart Federation; International Atherosclerosis Society; and International Associational for the study of obesity. Alberti KG, Eckel RH, Grimdy SM, Zimmet PZ, Cleeman JI, Donato KA, Fruchart JC et al. Circulation. 2009;120:1640-5.

3. Laaksonen DE., Niskanen L, Lakka HM, Lakka TA, Uusitupa M. Epidemiology and treatment of the metabolic syndrome. Ann Med. 2004;36: 33246.

4. Alberti KG, Zimmet P, Show J. Metabolic syndrome: a new world-wide definition: a consensus statement from the International Diabetes Federation. Diabet Med 2006;23:46980.

5. Haskell WL, Lee IM, Pate RR, Powell KE, Blair SN, Frankin BA, Macera CA, Heath GW, Thompson PD, Bauman A. Physical Activity and Public Health: Updated Recommendation for Adults from the American College of Sports Medicine and the American Heart Association. Med Sci Sport Exe. 2007; 39 (8) :1423-34.

6. Nguyen NT, Magno CP, Lane KT, Hinojosa MW, Lane JS. Association of Hypertension, Diabetes, and Metabolic Syndrome with Obesity. Diabetes, Dyslipidemia, and Metabolic Syndeome with
Obesity. Findings from the National Health and Nutrition Examination Survery, 1999 to 2004. J Am Coll Surg. 2008;207(6)

7. Spain CG,Franks BD. Healthy people 2010 ; physical activity and fitness. President's council physical fitness sport. President's council on physical fitness and sport research digest. 2001;3(13):1-16

8. Godin G, Shephard RJ. A simple method to assess exercise behaviour in the community. Can J Appl Sport Sci. 1985;10(3)141-6

9. Miler DJ, Freedson PS, Kline GM, Comparison of activity levels using the Caltrac accelerometer and five questionnaires. Med Sci Sports Exerc. 1994;26(3):376-82.

10. Godin G. The godin-shephard leisure-time physical activity questionnaire (Commentary). Health Fit J Canada. 2011;4(1).

11. Caroll S,Dudfield M. What is the relationship between exercise and metabolic abnormalities? A review of the metabolic syndrome. Sports Med.2004;34:371-418

12. Mackie BD, Zafaari AM. Physical activity and the Metaboic syndrome. Hospital Physician. 2006;26-38

13. Haskell WL, Lee IM, Pate RR, Powel KE, Blair SN, Franklin BA, Macera CA, Health GW, Thomson PD, Bauman A. Physical activity and public health: Updated recommendation for adults from the Americal college of sports Medicine and American Heart Association. Med Sci Sport Exe. 2007;39(8):1423-34

14. Eckel RH. The Metabolic syndrome. In: Fauci AS,Kasper DL,Longo DL, etal editors. Harrison's Principles of Medicine. $17^{\text {th }}$ ed. USA:Mc GrawHill companies,Inc;2008.p.1509-13

15. Mohan V, Gokulkrishnan K, Deepa R, Shantirani CS, Dutta M. Association of physical inactivity with components of metabolic syndrome and coronary artery disease-the Chennai Urban population study (CUPS no.15). Diabetes Med. 2005;22(9): 1206-11.

16. Cherell D, Vitool L,Michelle AW.Risk of dislipidemia in relation to level of physical activity among Thai professional and office workers. South Asian J Trop Med Public Health. 2008;39(5):932-41. 